\title{
A VIA DIPLOMÁTICA NA SOLUÇÃo PACÍFICA dOS LiTÍGIOS INTERNACIONAIS: A MEDIAÇÃO DE CONTADORA
}

\author{
Fredys Orlando Sorto \\ Professor Assistente da Faculdade de Direito da Universidade Federal da Paraíba
}

Resumo:

Este trabalho trata do primeiro plano global de paz para a América Central, apresentado pelo Grupo de Contadora, hoje denominado Grupo do Rio.

Os esforços de Contadora resultaram em um tratado de paz para a região. Este tratado constitui o ponto culminante do largo processo de negociação diplomática, que conduziu à pacificação regional.

Abstract:

This article refers to the first Global Central American Peace Plan, so presented by Contadora Group, currently Rio Group. Contadora efforts turned out in a Peace Treaty for that region.

This treaty is itself the culmination of the long diplomatic negotiation process that led to the regional pacification.

\section{Sumário:}

1. Introdução

2. Declaração de Cancún

3. Documento de Objetivos

4. Negociação do Tratado Geral de Paz

5. Ata de Contadora para a Paz e a Cooperação na América Central

\section{INTRODUÇÃO}

A mediação consiste num ato amistoso individual ou coletivo, mediante o qual (...) um ou mais Estados se fazem intermediários oficiais de uma 
negociação para a solução pacífica de um litígio entre outros Estados. ${ }^{1}$ Pode ser exercida também por uma organização internacional ou por um cidadão de grande prestígio. $\mathrm{O}$ art. 11 do Pacto de Bogotá reza o seguinte: "O procedimento da mediação consiste em submeter a controvérsia a um ou mais governos americanos ou a um ou mais cidadãos eminentes de qualquer Estado Americano alheio à controvérsia." A principal característica da mediação reside no fato de o mediador desempenhar um papel ativo nas negociações, para apresentar, no final, uma proposta concreta de solução às partes em litígio. ${ }^{2}$ Esta intervenção direta do mediador nas negociações constitui o traço mais significativo da distinção entre a mediação e os bons ofícios (este meio tem participação mais discreta). A mediação, como meio de solução pacífica de controvérsias, acha-se entre aqueles indicados pelos arts. 33 da Carta da ONU e 24 da Carta da OEA.

O denominado Grupo de Contadora (Colômbia, México, Panamá e Venezuela) exerceu, de 1983 a 1986, o importante papel de mediador na crise da América Central. Contadora enquadra-se mais, dentre os processos pacíficos, no procedimento da mediação, em decorrência da sua participação ativa nas negociações entre as partes em litígio (Guatemala, El Salvador, Honduras, Nicarágua e Costa Rica). Essas negociações resultaram na elaboração de um tratado de paz para os diversos conflitos, que constituem a crise regional. Trata-se da chamada Ata de Contadora para a Paz e a Cooperação na América Central. ${ }^{3}$

1. Hildebrando Accioli, Tratado de Direito Internacional Público, $2^{2}$ ed., Rio de Janeiro, Ministério das Relações Exteriores, 1956, v. 2, p. 16.

2. Cf. Guido Fernando Silva Soares, Órgãos das Soluções Extrajudiciais de Litígios, São Paulo, Revista dos Tribunais, 1985 , p. 39-54.

"O Estado mediador participa da negociação e propõe uma solução do litígio." Rousseau, Charles. Direito Internacional Público, 3' ed, Barcelona, Ariel, 1966, p.487.

"A mediação consiste numa gestão direta de negociações entre as partes em conflito sobre as propostas feitas pelo mediador." Oppenheim, L. Tratado de Derecho Internacional Público, Barcelona, Bosch, 1966, v. 1, t. 2, p. 11.

3. Documentos consultados: 1) Tratado que estabelece a Comunidade Democrática da América Central (San José), assinado em 19 de janeiro de 1982;2) Discurso do Presidente Reagan no Congresso, 27 de abril de 1983; 3) Resolução n. 530 do Conselho de Segurança, 19 de maio de 1983; 4) Declaração de Cancún sobre a Paz na América Central (México), 17 de julho de 1983; 5) Mensagens do Grupo de Contadora a Reagan e a Castro (Cancún), 17 de julho de 1983; 6) Proposta de Paz da Guatemala, de El Salvador, de Honduras e de Costa Rica (Guatemala), 20 de julho de 1983; 7) Carta de Fidel Castro ao Grupo de Contadora, 21 de julho de 1983; 8) Carta do Presidente Reagan aos lideres do Grupo de Contadora, 26 de julho de 1983; 9) Grupo de Contadora; Documento de Objetivos (Panamá), 7 de setembro de 1983 ; 10) Projeto de tratado para garantir o respeito mútuo, a paz e a seguraná entre a República da Nicarágua e os Estados Unidos (apresentado pela Nicarágua em Washington), 15 de outubro de $1983 ;$ 11) Projeto de Tratado Paz, de Amizade e de Cooperação entre as Repúblicas de Honduras e da Nicarágua, outubro de 1983 ; 12) Projeto de acordo para ajudar à solução pacífica do conflito armado na 


\section{DECLARAÇÃO DE CANCÚN}

A guerra das Malvinas, na qual os Estados Unidos intervieram em favor de uma potência extracontinental, teve como efeito o enfraquecimento abrupto do sistema interamericano. ${ }^{4}$ Ficou evidente que a OEA tinha-se tornado inoperante na solução dos problemas continentais. ${ }^{5}$ A partir daí, a aplicação de medidas de força na América Central, no âmbito do sistema interamericano, passou a ser

República de El Salvador, outubro de $1983 ; 13$ ) Projeto de tratado geral sobre a manutenção da paz e da segurança, bem como sobre as relações de amizade e de cooperação entre as repúblicas da América Central, outubro de 1983 ; 14) Carta do Presidente de Honduras ao Grupo de Contadora, 6 de junho de 1984; 15) Carta do Grupo de Contadora aos presidentes da América Central, 9 de junho de 1984; 16) Carta do Presidente de Honduras ao Grupo de Contadora, 27 de junho de 1984; 17) Comunicado conjunto dos chanceleres do Grupo de Contadora e os da América Central, 7 de setembro de 1984; 18) Carta dos chanceleres de Contadora aos presidentes centro-americanos, 7 de setembro de $1984 ; 20$ ) Comunicado dos chanceleres do grupos de Contadora e de Apoio (Washington), 10 de fevereiro de 1986; 21) Comunicado de Punta del Este dos chanceleres dos grupos de Contadora e de Apoio, 28 de fevereiro de 1986; 22) Comunicado conjunto da reunião de Panamá, emitido pelos chanceleres dos grupos de Contadora e de Apoio e os da América Central, 7 de abril de 1986; 23) palestra proferida por José Napoleón Duarte (Buenos Aires), 15 de maio de 1986; 24) Ata de Contadora para a Paz e a Cooperação na América Central (Panamá) , 6 de junho de 1986; 25) Mensagem do Panamá, dos chanceleres dos grupos de Contadora e de Apoio, 7 de junho de 1986; 26) Declaração do Grupo de Contadora e do Grupo de Apoio e dos chanceleres da América Central (Panamá), 7 de junho de 1986; 27) Declaração dos chanceleres dos grupos de Contadora e de Apoio (Nova Iorque), $1^{\circ}$ de outubro de $1986 ; 28$ ) Declaração dos grupos de Contadora e de Apoio no XVI periodo de sessões da Assembléia Geral da OEA, 14 de novembro de 1986; 29) Declaração do Rio de Janeiro dos chanceleres dos grupos de Contadora e de Apoio, 18 de dezembro de 1986; 30) Comunicado de chanceleres dos grupos de Contadora e de Apoio (México), 21 de janeiro de 1987; 31) Comunicado-político-conjunto da Comunidade Econômica Européia, da América Central e do Grupo de Contadora (Guatemala, 10 de fevereiro de 1987; 32) Comunicado-econômico-conjunto da Comunidade Econômica Européia, da América Central e do Grupo de Contadora (Guatemala), 10 de fevereiro de 1987 ; 33) Comunicado conjunto dos presidentes do México e da Guatemala (Guatemala), 10 de abril de 1987; 34) Declaração de Buenos Aires dos chanceleres dos grupos de Contadora e de Apoio, 13 de abril de 1987; 35) Comunicado dos chanceleres dos grupos de Contadora e de Apoio (San Carlos de Bariloche), 16 de abril de 1987 ; 36) Comunicado dos chanceleres dos grupos de Contadora e de Apoio (São Paulo), 9 de agosto de 1987; 37) Compromisso de Acapulco para a Paz, o Desenvolvimento e a Democracia, 29 de novembro de 1987.

4. O professor Guido Fernando Silva Soares define o sistema interamericano como o "tripé construído sobre três tratados", a saber: a Carta da Organização dos Estados Americanos, o Tratado Interamericano de Soluções Pacíficas (Pacto de Bogotá) e o Tratado Interamericano de Assistência Recíproca (TIAR). Soares, Guido F. Silva "Exxamen de los principales tratados bilaterales y multilaterales vigentes entre países latino americanos (no pertenecientes al sistema interamericano) sobre solución pacifica de conflictos, con especial énfasis en su posible hermeticidad y aplicaciones." In: Integración solidaria para el mantenimiento de la paz en América Latina, Caracas, Instituto de Altos Estudios de América Latina, |1989| p. 135.

5. Cf. Herrera Zúniga, René $\varepsilon$ Chavarría, Manuel. México en Contadora: una búsqueda de límites a su compromiso en Centroamérica. Foro Internacional, México, 24 (4): 458-83, p. 466; abr./jun. 1984, Bell, Peter D. La búsqueda de la paz en Centroamérica: fortalecer Contadora. Relaciones Internacionales, Heredia, (8-9): 9-14, 1984, p. 10-11; Flores Pinel, Fernando. Ni por la guerra ni por la paz: el impase del Grupo de Contadora. Estudios Centroamericanos, San Salvador, 38 (415-416): 531-4, mayo/jun. 1983. 
praticamente inviável. No que respeita ao sistema da $\mathrm{ONU}$, este não oferece suficientes garantias a todas as partes. ${ }^{6} \mathrm{O}$ conflito centro-americano, por seu turno, acirrou-se em 1982, a tal ponto que a guerra generalizada e/ou a intervenção militar direta dos Estados Unidos pareciam ser as únicas op̧ões. O Grupo de Contadora foi constituído nestas circunstâncias. ' Contadora foi estabelecido com dois objetivos primordiais: 1. o de prestar sua ativa colaboração para elaborar um tratado de paz que regulasse, de maneira justa e equilibrada, as relações entre os Estados da América Central; 2. o de identificar as condições básicas para que o tratado fosse assinado, cumprido e respeitado pelas partes.

Nos dias 8 e 9 de janeiro de 1983, na llha de Contadora (Panamá), foi criado o Grupo de Contadora pelos chanceleres da Colômbia, do México, do Panamá e da Venezuela. ${ }^{8}$ Segundo o comunicado oficial dessa reunião, os chanceleres consideraram necessário intensificar o diálogo entre os países latinoamericanos como o meio mais eficaz de superar os problemas políticos, econômicos e sociais, os quais comprometem a paz, a democracia, a estabilidade e o desenvolvimento dos povos do Continente. Sobre a situação na América Central, examinaram o complexo panorama existente, bem como os processos políticos que ocorriam na área, a inter-relação desses processos e as conseqüências para a paz e para a estabilidade da América Latina. Em decorrência disso, expressaram grande preocupação pela ingerência externa direta e indireta nos conflitos da América Central e admitiram que seria totalmente indesejável a inserção desses conflitos no contexto Leste-Oeste. Por isso, coincidiram na necessidade de eliminar os fatores

6. Cf. Hernández Alcerro, Jorge Ramón. La crisis centroamericana y las negociaciones de Contadora, Revista de Derecho, Tegucigalpa, UNAH, 17 (18): 23-35, 1986, p. 28.

7 Veja-se Trindade, Antônio Augusto Cançado. Aspectos institucionais das relações internacionais na América Latina. Política e estratégia. São Paulo, 2 (1): 28-52, jan./mar. 1984. p. 40 e 43.

8. Antecedentes. A declaração franco-mexicana de 1981 propunha, no sistema das Nações Unidas, uma solução negociada para o conflito salvadorenho.

Em 19 de janeiro de 1982, o chanceler de El Salvador, o de Honduras e o da Costa Rica assinaram um documento instituindo a Comunidade Democrática da América Central. Neste documento, os Estados manifestaram a sua vontade de solucionar os problemas sociais, econômicos e políticos. Dentre os propósitos políticos da Comunidade destacam-se: o respeito aos direitos humanos e a afirmação do direito individual de recorrer a medidas de segurança coletiva, de acordo com os tratados vigentes. Dentre os propósitos econômicos: a crią̧ão de uma comunidade econômica.

Em 23 de março de 1982, Honduras apresentou no Conselho Permanente da OEA um plano de paz para a América Central.

Em agosto de 1982, em Cancún, o chanceler do México e o da Venezuela analisaram a crítica situação regional. Nesta oportunidade, Honduras e Nicarágua foram incentivadas ao diálogo a às negociações bilaterais para a solução das diferenças. 
externos que contribuíram para o agravamento da crise regional. Com esse objetivo formularam uma convocação urgente dos governos da América Central, para que, mediante o diálogo e a negociação, se reduzissem as tensões e se estabelecessem as bases para uma convivência pacifica permanente, de respeito mútuo entre os Estados. Dar-se-ia atenção especial à obrigação de não recorrer à ameaça ou ao emprego da força nas relações internacionais e de abster-se de praticar atos que pudessem agravar a situação. Os chanceleres recordaram as diversas iniciativas de pacificação regional e analisaram a possibilidade de novas ações, com o apoio de outros países do Continente.

Os membros do Grupo de Contadora, em seguida, intensificaram o trabalho diplomático junto aos governos centro-americanos. Em abril, receberam destes a autorização para iniciar o processo de negociação. A primeira reunião conjunta, no entanto, fracassou. Em maio de 1983, ocorreu a segunda reunião. Nesta oportunidade, foi aprovada uma agenda de trabalho, na qual se delimitavam as áreas de atrito que seriam objeto de diálogo e de negociação, de acordo com a seguinte estrutura: 1. aspecto conceitual (questões teóricas de direito internacional); 2. problemas políticos e de segurança; 3. problemas econômicos e sociais; 4 . execução e fiscalização dos acordos. Aqui estão incluídos, basicamente, os seis pontos do Plano de Paz apresentado por Honduras, no Conselho Permanente da OEA, em março de 1982 .

A terceira reunião conjunta ocorreu em julho de 1983. Nesta conferência, a Guatemala, El Salvador, Honduras e Costa Rica apresentaram o documento chamado Bases para a Paz na América Central. Neste, se comprometiam a continuar discutindo as quatro vertentes prioritárias que precisavam ser desenvolvidas para superar a crise regional, ou seja, os pontos aprovados na agenda de trabalho da reunião anterior.

Em 17 de julho, celebrou-se, em Cancún (México), a Conferência de Cúpula dos chefes de Estado dos países-membros do Grupo de Contadora. Esta reunião foi de extraordinária importância. Nela foram lançadas as diretrizes de um

9 Os seis pontos são: 1) desarme geral; 2) redução dos acessores militares; 3) suspensão do tráfico de armas; 4) fiscalização internacional; 5) respeito às fronteiras existentes; 6) diálogo multilateral permanente.

Paz Bamica, Edgardo. Lecciones de Derecho Internacional Público, Madrid, Cultura hispanica, 1984. p. 409-10; Paz Aguilar, Emesto. Evolución reciente de la política exterior de Honduras: balance y perspectivas. Relaciones Internacionales, Heredia, 4 (6):123-30, 1986. Número extraordinário. 124. 
programa geral de paz e de desenvolvimento para a América Central. Conforme a Declaração de Cancún, o uso da força como alternativa de solução não resolve, senão que agrava, as tensões subjacentes. A paz só será alcançada, então, na medida em que forem respeitados os seguintes princípios fundamentais de convivência internacional: a não-intervenção, a autodeterminação, a cooperação para o desenvolvimento econômico e social, a solução pacífica dos litígios, bem como a manifestação livre e autêntica da vontade popular.

Com a mira essencial de acelerar o processo de pacificação na América Central, os presidentes determinaram, na Conferência de Cancún, as diretrizes gerais de um projeto de paz a ser proposto aos governos centroamericanos (dos quais depende, fundamentalmente, a criação de condições favoráveis à paz). As matérias capitais desse projeto são: fiscalização de armamentos; supressão de assessores militares estrangeiros; criação de zonas desmilitarizadas; interdição do uso do território para realizar ações políticas ou militares de desestabilização dos governos de outros Estados; erradicação do tráfico de armas; proibição de outras formas de agressão ou de ingerência nos assuntos internos de qualquer um dos países da área. Para tornar efetivo o seu plano de paz, Contadora propôs a celebração de vários acordos políticos destinados a garantir a pacificação regional.

As medidas reservadas à eliminação dos fatores que alteram a paz regional - de acordo com a mesma declaração - devem ser acompanhadas pelo fortalecimento das instituições democráticas e pela observância dos direitos humanos. Diante disso, deve se enfrentar o atraso econômico que está na raiz da instabilidade regional e constitui a causa direta da maioria dos conflitos.

Devem-se, também, fortalecer-se os mecanismos de integração, incrementar-se $o$ comércio regional e aproveitar-se as possibilidades de aperfeiçoamento industrial. "A América Central precisa da paz e ao mesmo tempo do desenvolvimento. A crise reproduz as tendências da guerra e estas seriam incontroláveis no seio de sociedades militarizadas. $" 10$

10 Valero, Ricardo. América Central entre la paz e la tormenta, Revista Mexicana de Politica Exterior, México, (13): 15-8, oct./dic. 1986, p. 18. 
Com fundamento nos lineamentos gerais acima referidos, os chefes de Estado presentes à Conferência de Cancún "1 autorizaram os seus respectivos chanceleres a elaborar propostas especificas, para serem submetidas à consideração dos governos dos países centro-americanos, na subseqüente reunião conjunta de chanceleres.

A seguir, o Grupo de Contadora enviou mensagens ao governo de Cuba e ao dos Estados Unidos, respectivamente. "Somos sinceros partidários da substituição do confronto pelo diálogo" respondeu o Governo cubano. ${ }^{12}$ Já o Presidente Reagan replicou dando sua visão pessoal da crise e afirmando ser a OEA o "mecanismo apropriado para assegurar que sejam cumpridas as promessas por aqueles que as têm contrariado" (os sandinistas).

Infere-se disso que os Estados Unidos não apoiaram a mediação de Contadora desde o começo. A incompatibilidade entre os objetivos do Grupo de Contadora e a política externa norte-americana acha-se expressamente no denominado Informe Kissinger. Outros acontecimentos concomitantes com as iniciativas de negociação de Contadora, que confirmam esse antagonismo, são: o apoio aos contras, as manobras militares de grande porte (envolvendo até dezesseis mil soldados), a instalação de uma base militar em Puerto Castilla, a ampliação da estrutura militar de Honduras ${ }_{14}^{13}$ e a consideração dos sandinistas como ameaça à segurança dos Estados Unidos.

11. Belisario Betancur (Colômbia), Miguel de la Madrid (México), Ricardo de la Espriella (Panamá) e Luis Herrera Campis (Venezuela).

12. Segundo Grabendorf, a internacionalização da crise da América Central deu lugar (durante a Administração Reagan) à formação de três tendências políticas concorrentes: 1) aliança statu quo (Estados Unidos, União Democrata Cristã Mundial, Israel, os govemos da Guatemala, de El Salvador, de Honduras e de Costa Rica); 2) aliança pró-câmbio social (México, Internacional Socialista, França, Panamá, Venezuela, a partir do conflito das Malvinas, e Colômbia, depois que Betancur chegou ao poder); 3) aliança pró-mudança revolucionária (Cuba, paises socialistas, Líbia, Organização para a libertação da Palestina, Nicarágua e movimentos guerrilheiros). Cf. Grabendorff, Wolf. El papel de las potencias regionales en la crisis centro-americana: comparación entre México, Venezuela, Cuba y Colombia. Revista Occidental, Tijuana, 1(4): 437-60, 1984. Edición especial. p. 459.

13. Honduras passou de "(...) encravado de bananeiras a encravado militar (...). Em conclusão, a política de Reagan na América Central nos conduz à ditadura, nos condena à pobreza e nos empurra à guerra. " Paz Aguilar, Emesto. ob. cit. p. 128-9; cf. Diaz-Callejas, Apolinar. Contadora: desafio al imperio. Bogotá, Oveja Negra, 1985. p. 169.

14. Kissinger, Henry. Em busca da paz na América Central. O Estado de S. Paulo. São Paulo, 6 de setembro de 1987. Exterior. p. 8. 


\section{DOCUMENTO DE OBJETTVOS}

A quarta reunião de chanceleres do Grupo de Contadora e da América Central aconteceu em 7 de setembro de 1983 (Panamá).

Nesta ocasião, foi adotado um importante instrumento. Trata-se do denominado Documento de Objetivos, o qual reúne as propostas de pacificação, produzidas na região, e as de Cancún. Nele se consagram os compromissos fundamentais para alcançar a paz, a democracia, a segurança, a estabilidade e a cooperação para o desenvolvimento econômico e social da América Central.

Afirma-se, no referido documento que, dada a situação reinante na América Central, constitui requisito essencial para a solução da crise, que se observem, mormente, os seguintes princípios de direito internacional: livre determinação dos povos; não-intervenção; igualdade soberana dos Estados; solução pacífica de controvérsias; abstenção do recurso à ameaça ou ao uso da força; respeito à integridade territorial dos Estados; pluralismo em suas diversas manifestações; plena observância das instituições democráticas; fomento à justiça social; cooperação internacional para o desenvolvimento; respeito e promoção dos direitos humanos; proscrição do terrorismo e da subversão.

No Documento de Objetivos manifesta-se, também, a decisão das partes em alcançar certos objetivos, dentre outros: 1. promover a distensão e pôr termo aos conflitos, abstendo-se, para tanto, de realizar ações que coloquem em risco a confiança política ou que obstaculizem a paz, a segurança e a estabilidade da região; 2. respeitar, estritamente, os princípios de direito internacional (enunciados acima) e adotar medidas que conduzam ao aperfeiçoamento de sistemas democráticos, representativos e pluralistas; 3. promover a reconciliação nacional onde se tenham produzido divisões sociais; 4 . criar condições para garantir a segurança internacional, a integridade e a soberania dos Estados centroamericanos; 5. iniciar negociações para reduzir os armamentos e os efetivos militares; 6. proibir a instalação de bases militares ou qualquer outra forma de ingerência externa; 7. reduzir e eliminar a presença de assessores militares estrangeiros; 8. estabelecer mecanismos de fiscalização regional para impedir o tráfico de armas; 9. suspender o incentivo ou apoio a atos de terrorismo, de subversão ou de sabotagem nos países da área; 10 . prosseguir na ajuda humanitária destinada aos desabrigados e aos refugiados, propiciando condições que permitam a 
repatriação voluntária; 11. empreender programas de desenvolvimento econômico e social; 12. revitalizar e normalizar os mecanismos de integração econômica; 13. agenciar recursos financeiros junto à comunidade internacional, para reativar o comércio intra-regional, corrigir os problemas de balança de pagamentos, apoiar programas de ampliação e reestruturação dos sistemas produtivos e estimular os projetos de investimento a médio e a longo prazo.

Com base no direito internacional, nas resoluções da ONU e na Declaração de Cancún, a Nicarágua apresentou, em 15 de outubro de 1983, vários projetos de tratados. Os sandinistas buscavam com isso, de um lado, esgotar todos os recursos possíveis e permitidos de solução pacífica e, de outro, publicidade. ${ }^{15}$ Os Estado Unidos, naturalmente, não iriam fazer acordo nenhum com o governo da Nicarágua, o qual estavam empenhados em derrubar. Partindo-se do fato de o governo de Washington ter rejeitado um acordo pacífico de indole multilateral (processo de Contadora), não há imaginar, então, a aceitação de um tratado bilateral com um Estado que consideravam totalitário. E o governo sandinista sabia disso. Razão por que se afirma que a oferta nicaragüense tinha também objetivos propagandistas.

Em janeiro de 1984, foi adotado outro documento de grande relevância no âmbito de Contadora: o denominado Normas para Execução dos Compromissos Assumidos no Documento de Objetivos. Nesta ocasião, foram constituídas comissões de trabalho por sugestão do governo de Honduras. Ao todo formaram-se três comissões, entre as quais foram divididos os temas seguintes: política, segurança e questões sócio-econômicas. Formou-se, além disso, um grupo técnico de assessoria e acompanhamento das ações previstas no Documento de Objetivos. Em abril do mesmo ano, os informes das comissões foram coligidos num

15 Quanto à letra do tratado proposto aos Estados Unidos pela Nicarágua, estipula-se aí o compromisso de não recorrer à força nas relações internacionais ou ao emprego de força contra a integridade territorial ou a independência politica como meio de solução dos litígios (art. $\left.1^{\circ}\right)$. Em suma, o reconhecimento do direito inalienável do Estado da Nicarágua à sua independência e autodeterminação, ou seja, à sua condição de Estado soberano (art. $5^{\circ}$ ). Em consequêencia, o direito de escolher livremente o seu sistema econômico, social, político e cultural sem interferência externa (art. 13). A Nicarágua se compromete, em troca, a não permitir a utlização do seu território para ameaçar a segurança dos Estados Unidos ou para agredir qualquer outro Estado (art. $6^{\circ}$ ).

A Nicarágua apresentou também um projeto de tratado de paz a Honduras e um acordo para a solução do conflito armado de El Salvador. 
documento intitulado Ata de Contadora para a Paz e a Cooperação na América Central.

\section{NEGOCIAÇÃO DO TRATADO GERAL DE PAZ}

Em 9 de junho de 1984, foi apresentado aos governos da América Central o anteprojeto de tratado denominado Ata de Contadora para a Paz e a Cooperação na América Central. Este anteprojeto representa um trabalho "(...) de ordenação, de integração e de sistematização (...) e constitui um documento da maior importância como fundamento para a negociação dos acordos com força jurídica vinculatória para a solução pacífica e negociada dos conflitos. " anteprojeto da Ata se elaborou com base nos compromissos e nas recomendações adotadas por consenso, nas três comissões de trabalho.

Dada a intrincada questão regional, o esquema normativo adotado por Contadora, como não poderia deixar de ser, constitui um reflexo expressivo da complexa situação que ele aborda. Quanto ao alcance e à natureza jurídica da Ata, vale o comentário abaixo:

"Não existe nenhuma norma de direito internacional que impeça aos Estados de escolher a forma que desejem dar aos instrumentos nos quais manifestem a sua vontade politica de solução das diferenças. $O$ que proporciona a natureza jurídica a esses instrumentos é a vontade expressa pelas partes ao determinar o alcance das suas obrigações. "17

Contudo, nas reuniões de junho e nas de agosto, interromperam-se as negociações. Surgiram dificuldades de estabelecer compromissos, principalmente quanto à segurança, aos mecanismos de verificação e de fiscalização dos acordos. Por isso, em 7 de setembro de 1984, na sétima reunião dos chanceleres da América Central com os do Grupo de Contadora, foi apresentado o anteprojeto de tratado com as modificações pertinentes, isto é, a Ata Revisada de Contadora para a Paz e a Cooperação na América Central. Este documento alargava os compromissos e superava as objeções feitas à sistematização inicial. O Grupo de Contadora, em mensagem que acompanhou a Ata Revisada, fez um chamado insistente aos

16. Paz Barnica, Edgardo. ob. cit. p. 427.

17 Carta de 9 de julho de 1984, que acompanhou a primeira versão da Ata de Contadora. 
governos centro-americanos com o intuito de lograr a adoção imediata - por causa da ameaça persistente de ruptura da paz - dos compromissos jurídicos contidos na Ata Revisada. Contadora manifestou, ainda, a necessidade de respeito à livre determinação e de substituição da força pela negociação política, por parte dos Estados que têm interesses e vínculos na região.

No comunicado de 7 de setembro, do mesmo ano, os chanceleres do Grupo de Contadora reconheceram os avanços obtidos pela negociação diplomática e o amplo apoio internacional ao processo de pacificação. Não obstante, manifestaram preocupação com a continuidade da militarização, das agressões armadas, dos incidentes fronteiriços, das ações de desestabilização, da presença militar estrangeira e da deterioração econômica e social da América Central.

O Subsecretário Adjunto de Assuntos Interamericanos, Stephen W. Bosworth declarou que as manobras militares, acima referidas, se realizavam para que os aliados dos Estados Unidos na região (El Salvador, Honduras e Costa Rica) não se considerassem subordinados à Nicarágua, no sistema de Contadora. ${ }^{18} \mathrm{O}$ Informe Kissinger, não obstante, já havia deixado clara a posição do governo de Washington para com o processo de pacificação de Contadora. Este não poderia ser usado como substituto da política norte-americana. Em 27 de abril de 1983, quando discursou no Congresso, o Presidente Reagan afirmou que a segurança dos Estados Unidos estava comprometida na América Central e, portanto, era preciso derrubar o governo da Nicarágua. E concluiu: "(...) se não podemos defender a nós mesmos nessa região, não podemos aspirar a prevalecer noutras partes."

Enquanto o referido Subsecretário, justificava as manobras militares, El Salvador, Honduras e Costa Rica indicavam a OEA como o foro mais adequado para a pacificação, que era, exatamente, a posição dos Estados Unidos. A este respeito, o chanceler do México, Bernardo Sepúlveda, foi incisivo: "(...) a OEA não é o meio idôneo", afirmou. Contudo, em 3 de outubro de 1984, a Ata Revisada foi apresentada ao Conselho de Segurança da ONU.

Outro dado que confirma a falta de apoio dos Estados Unidos ao Grupo de Contadora reside na pretensão de isolar o México dentro do Grupo e fazê-

18. Morales, Cesáreo. Contadora y la estrategia de Esados Unidos, en Centroamérica: evaluación y perspectivas. Cuadernos Americanos, México, 44 (1): 45-62, ene./feb. 1985. p. 50.

19. Apud id., ibid, p. 52-53. 
lo parecer um aliado incondicional dos sandinistas, segundo afirmou o Conselho de Assuntos Hemisféricos. ${ }^{20}$ Gonzalo Facio segue este mesmo raciocínio, pois afirma ele que o propósito mexicano, ao formar o Grupo de Contadora, foi o de permitir a consolidação do regime totalitário da Nicarágua, ou seja, uma base de subversão do poder soviético.

Em 17 de outubro de 1984, por iniciativa de Honduras, ocorreu uma reunião em Tegucigalpa. El Salvador, Honduras e Costa Rica fizeram considerações à Ata Revisada. Resultou disso a chamada Versão de Tegucigalpa (da Ata de Contadora). Este documento, apoiado pelos Estados Unidos, incluía a realização de manobras militares e colocava travas à questão da saída dos assessores militares. Isto resultou em um impasse nas negociações. Em conseqüência, a Ata não foi assinada.

Mas a participação de Contadora não se limitou à elaboração de um tratado geral de paz. Sua participação foi imprescindível para a aproximação da região com a Comunidade Econômica Européia (CEE). Com efeito, a mediação de Contadora possibilitou a realização de várias conferências entre os chanceleres da CEE e os da América Central. A primeira se deu em San José, em setembro de 1984; a segunda, em Luxemburgo, em novembro de 1985; e a terceira, na Guatemala, em fevereiro de 1987. Coube a Contadora, nestas conferências, o papel de aglutinador da política latino-americana. ${ }^{22}$ Deste modo, além de sua tarefa de mediador, mostrou-se hábil interlocutor nessas negociações multilaterais. $O$ objetivo do acercamento com a CEE era o de procurar o apoio de um aliado de "(..) peso politico e econômico importante para que o ajudasse a 'convencer' os Estados Unidos da necessidade de modificar a sua política para a América Central." apoio da CEE à Ata de Contadora e a concessão de ajuda econômica ${ }^{24}$ foram

20. Id., ibid., p. 54.

21. Facio, Gonzalo J. La paz de Centroamérica y la acción del Grupo de Contadora. Relaciones Internacionales, Heredia, (8-9): 23-35, 19984, p. 26 e 33.

22. Pelicer, Olga. Reflexiones sobre la accion del Grupo de Contadora. Estudios Centroamericanos, San Salvador, 41 (456): 898-906, oct. 1986. p. 901.

23. Treviño Huerta, Luisa. Contadora: punto de encuentro entre América Latina y Europa Occidental. Revista de Estudios Internacionales, Madrid, 7(3): 821-36, jul./set. 1986. p. 828. de 1985 .

24. A CEE assinou com os países da América Central um acordo de cooperação, em 12 de novembro

A terceira conferência foi celebrada na cidade da Guatemala, em 10 de fevereiro de 1987. A CEE, O Grupo de Contadora e a América Central reafirmaram o compromisso de institucionalizar e 
considerados pelos Estados Unidos como uma intromissão européia numa zona que constitui o seu "primeiro cinturão de segurança."

A Versão de Tegucigalpa estancara as negociações diplomáticas. $\mathrm{O}$ processo de Contadora só foi retomado na décima reunião, em março de 1985 , em Brasília. Neste ensejo, Honduras, El Salvador e Costa Rica apresentaram o documento denominado Estatuto sobre o Mecanismo de Verificação e Fiscalização em Matéria de Segurança, que completava a Versão de Tegucigalpa.

Em agosto de 1985, na reunião de Cartagena, a Argentina, o Brasil, o Peru e o Uruguai constituíram o conhecido Grupo de Apoio a Contadora. Este acontecimento revitalizou as ações de Contadora, as quais tinham sido interrompidas pelos artifícios que resultaram na elaboração da Ata de Tegucigalpa.

Em 12 de janeiro de 1986, foi elucidado um dos documentos mais significativos, produzidos no âmbito de Contadora. Trata-se da Mensagem de Caraballeda para a Paz, a Segurança e a Democracia na América Central. Nesta Mensagem são recapitulados os esforços diplomáticos até então realizados por Contadora. Constitui, também, uma tentativa de revitalização do processo diplomático, tendo em vista a assinatura da Ata de Contadora. No documento de Caraballeda são propostos os seguintes pontos fundamentais: 1. retomada das negociações para a assinatura da Ata; 2. fim do apoio externo às forças irregulares e aos grupos guerrilheiros; 3 . congelamento das aquisições de armamentos e a sua redução; 4. suspensão das manobras militares internacionais; 5. redução progressiva, até eliminar a presença de assessores e de instalações militares estrangeiras; 6. reconciliação nacional, vigência dos direitos humanos e das liberdades individuais; 7. promoção da cooperação regional e internacional, visando-se aliviar os problemas econômicos e sociais que afetam a região.

Os chanceleres dos grupos de Contadora e de Apoio, reunidos em abril de 1986, convidaram os governos centro-americanos para, na cidade do Panamá, encerrar oficialmente as negociações do texto da Ata de Contadora e

aprofundar o diálogo político, mediante reuniōes ministeriais anuais. Segundo o comunicado oficial dessa conferência, o diálogo político tinha como objetivo o de contribuir para encontrar uma solução negociada, regional, global e pacifica, acompanhada dos mecanismos adequados de verificação e de fiscalização para pôr termo à violência, à instabilidade e promover o respeito ao Direito Internacional.

25. Treviño Huerta, Luisa, ob. cit., p. 831-2. 
proceder à sua assinatura. ${ }^{26}$ Quanto aos pontos pendentes (fiscalização e redução de armamentos e manobras militares internacionais), os presidentes da América Central foram instados, no sentido de iniciar negociações com base nas propostas já apresentadas. Os grupos de Contadora e de Apoio, além disso, reafirmaram que, para alcançar a paz, seria necessário que todas as partes e os países com vínculos e interesses na América Central se abstivessem de proporcionar ajuda às forças irregulares (contras) e aos movimentos insurrecionais (guerrilhas).

\section{ATA DE CONTADORA PARA A PAZ E A COOPERAÇÃO NA AMÉRICA CENTRAL}

Em 6 de julho de 1986, foi apresentada a última versão da Ata de Contadora para a Paz e a Cooperação na América Central. Nesta ocasião, afirmou-se que, para avançar no processo de negociação e alcançar o objetivo final, a paz, era preciso aceitar três ordens fundamentais de compromissos: 1. não utilizar o território nacional para, a partir dele, agredir outro país, nem proporcionar ajuda militar ou logística a forças irregulares ou a grupos guerrilheiros; 2. não fazer parte de alianças militares ou políticas que ameacem, direta ou indiretamente, a paz e a segurança na região, colocando-a no conflito Leste-Oeste; 3. não haver apoio militar ou logístico de nenhuma potência às forças irregulares ou aos grupos guerrilheiros que atuam ou possam vir a atuar na América Central, ou utilize ou ameace utilizar a força como meio para derrubar um governo da região.

Com a apresentação da Ata de Contadora, o grupo mediador pretendia concluir o processo de negociação e, em consequência, alcançar a paz efetiva. Quanto à Ata, esta tem uma composição complexa, devido à existência de grande quantidade de princípios, de métodos pacíficos de solução, de compromissos e de mecanismos de execução e de verificação dos acordos. ${ }^{27}$ A Ata de Contadora oferece "(...) um diagnóstico dos problemas da região e uma visão integrada da solução que poderia dar-se-lhes. "

26. Na reunião esteve presente Hans Van Der Broek, chanceler dos Países Baixos e Presidente do Conselho de Ministros da CEE.

27 Sepúlveda, César Opciones entre diplomacia y hememonia. La mision de Contadora. Revista Mexicana dePolítica Exterior, México, (17): 8-12, oct./dic. 1987. p. 11.

28. Pellicer, Olga, ob. cit., p. 900. 
Estrutura do Tratado - A Ata de Contadora reflete, em sua estrutura, a diversidade e a complexidade dos problemas específicos da América Central, os quais são catalogados no preâmbulo do Tratado.

A Ata está dividida em três partes.

A primeira contém quatro capítulos. Destes o primeiro é dedicado aos compromissos jurídicos gerais da submissão aos princípios de direito internacional, entre eles: renúncia à ameaça ou ao uso da força contra a integridade territorial ou a independência; solução pacífica das controvérsias; não-ingerência nos assuntos internos e renúncia às práticas discriminatórias nas relações econômicas entre os Estados, respeitando-se seus sistemas de organização política, econômica e social. O segundo trata dos acordos sobre assuntos políticos (distensão regional, reconciliação nacional, direitos humanos, processos eleitorais e cooperação parlamentar). O terceiro, o mais polêmico, cuida dos compromissos em assuntos de segurança (manobras militares, armamentos e efetivos militares, bases militares estrangeiras, assessores militares estrangeiros, tráfico de armas, proibição do apoio às forças irregulares, terrorismo, subversão ou sabotagem e sistemas de comunicação direta). $\mathrm{O}$ quarto trata dos assuntos econômicos e sociais (integração, comércio, cooperação, dívida externa e refugiados).

A segunda parte reporta-se aos acordos e matéria de execução e de acompanhamento. Esta parte tem por escopo a cabal observância da Ata de Contadora. Nesse sentido, instituem-se três mecanismos: 1. Conselho ad hoc para a Avaliação e o Acompanhamento dos Compromissos em Matéria de Política, de Refugiados e de Desabrigados; 2. Comissão de Verificação e de Fiscalização em Assuntos de Segurança; 3. Comissão ad hoc para a Avaliação e o Seguimento dos Compromissos Econômicos e Sociais. Todos os três são abordados detalhadamente no tocante à composição, à estrutura e às funções.

A terceira parte trata das Disposições Finais. Refere-se à natureza jurídica dos compromissos e às fórmulas de solução das controvérsias. Estabelece,

29. Conforme o preâmbulo da Ata de Contadora, a situação na América Central apresenta (1986) as seguintes características: grave deterioração da confiança política; profunda crise sócio-econômica; grave situação dos refugiados e dos desabrigados; incidentes fronteiriços; aumento do potencial bélico; tráfico de armas; presença de assessores militares estrangeiros; realização de manobras militares internacionais; existência de bases, de escolas e de instalações militares e outras formas de presença militar estrangeira, bem como o uso, por forças irregulares, do território de alguns paises para realizar ações de desestabilização de governos de outros Estados da América Central. 
também, o procedimento para a solução das diferenças na aplicação, no cumprimento ou na interpretação dos acordos. O prazo de vigência (cinco anos prorrogáveis) e o registro do Tratado (conforme o art. $2^{\circ}$ da Carta da ONU) são fixados, do mesmo modo, nas Disposições Finais.

A Ata de Contadora contém, ainda, um anexo (relativo a conceitos militares) e quatro protocolos adicionais. Estes ficaram abertos à assinatura dos Estados com vínculos e interesses na América Central. Os protocolos estabelecem o respeito aos acordos concluídos pelos países signatários.

Para concluir este assunto, deve-se dizer, em primeiro lugar, que a Ata de Contadora não foi assinada, mesmo sendo completa e tendo o grupo mediador o respaldo da sociedade internacional e de suas instituições. ${ }^{30}$ Em segundo lugar, convém fazer certas considerações a respeito da atuação do Grupo de Contadora e do Grupo de Apoio. Nesse sentido, César Sepúlveda destaca o desempenho do grupo mediador pelo emprego do método diplomático em suas melhores formas. Tal método compreende, segundo esse autor, a habilidade da persuasão, a negociação bem planejada, a consulta, a conciliação entre os antagonistas, a mediação, os bons oficios, a formação de comissões de investigação dos fatos, e, finalmente, a oferta de uma gradação de soluções políticas viáveis. Ou seja: compreende todos os métodos extrajudiciais de solução pacífica existentes.

Em conseqüência, o Grupo de Contadora evitou a guerra generalizada e conscientizou a sociedade internacional do perigo de conflagração continental. Evitou, ainda, a inserção da crise regional no confronto Leste-Oeste.

Há quem acredite que Contadora fracassou por não ter identificado, perante a opinião pública internacional, os Estados Unidos como causa real das tensões e dos conflitos na América Central. ${ }^{34}$ Para outros, Contadora não alcançou

30. Cf. As seguintes resoluções da Assembléia Geral da OEA: AG/Res. 675 (XIII-0/83); AG/Res. 702 (XIV-0/84); AG-Res. 770 (XV-0/85); e AG/Res. 831 (XVI-0/86).

31 Sepúlveda, César. ob. cit. p. 12; cf. Gutierrez, Carlos José. Costa Rica, Contadora y la democracia en Centroamérica. Relaciones Internacionales, Heredia, (10):63-8, 1985. p. 67.

32. Muños Ledo, Jesús Cabrera. La seguridad nacional de México y la pacificación de Centroamérica. Revista Mexicana de Politica Exterior, México, (16):11-3, jul./set. 1987. p. 8.

33. Todatlian, Juan Gabril. Contadora: tres opciones básicas. Nueva Sociedad, Caracas, (87):6-10, ene./feb. 1987. p. 8.

34. Diaz-Callejas, Apolinar, ob. cit., p. 10. 
totalmente seu objetivo, porque lhe faltou a cooperação norte-americana. ${ }^{35}$ Há, também, quem afirme que Contadora não atingiu os objetivos, pela diversidade de seus membros. Esta diversidade nos problemas e nos interesses de cada um dos membros teria, de acordo com este raciocínio, impossibilitado a aceitação da Ata.

A partir da reunião no Rio de Janeiro, em dezembro de 1986, quando foi criado o Mecanismo Permanente de Consulta e de Conciliação Politica, ${ }^{37}$ os grupos de Contadora e de Apoio se voltaram para temas mais gerais, tais como: cooperação político-econômica, integração e dívida externa.

Apesar disso, em janeiro de 1987, os chanceleres dos grupos de Contadora e de Apoio, junto com os secretários-gerais da ONU e da OEA, visitaram a América Central. A missão do Grupo dos Dez, como ficou conhecido, não levou nenhuma proposta concreta aos presidentes da região. No entanto, tinha objetivos bem precisos: o de solicitar a interpretação política dos governos em relação à crise; o de identificar as medidas necessárias à retomada das negociações e o de considerar as ações pertinentes à solução pacífica dos conflitos. Nesta oportunidade, Oscar Arias, Presidente da Costa Rica, apresentou ao Grupo dos Dez a sua proposta de paz regional, o denominado Plano Arias. Esta iniciativa redundou na assinatura de um tratado de paz. Trata-se de Esquipulas II.

A mediação do Grupo de Contadora na crise centro-americana, pelo que se sabe, findou em dezembro de 1986. Em seguida Contadora passou a chamarse Grupo dos Oito. Atualmente chama-se Grupo do Rio. Todos os países fundadores de Contadora fazem parte do Grupo do Rio, exceto o Panamá, que foi invadido (dezembro de 1989) e acha-se sob ocupação militar dos Estados Unidos.

35 Bell, Peter D. La búsqueda de la paz en Centroamérica: fortalecer Contadora. Relaciones Internacionales, Heredia, (8-9): 9-14, 1984.

36. Kaufman Purcell, Susan. La verdad sobre Contadora. Revista Occidental, Tijuana, 3(1): 47-69, 1986. p. 59-61.

37. O Mecanismo foi criado com duas funções básicas: efetuar consultas politicas e ajustar ações conjuntas. 


\section{REFERÊNCIAS BIBLIOGRÁFICAS}

ACCIOLY, Hildebrando. Tratado de direito internacional público. $2^{\mathrm{a}}$ ed. Rio de Janeiro : Ministério das Relações Exteriores, 1956. v. 2.

BELL, Peter O. La búsqueda de la paz en Centroamérica: fortalecer Contadora. Relaciones internacionales. Heredia, (8-9): 9-14, 1984.

DÍAZ CALLEJAS, Apolinar. Contadora: desafio al imperio. Bogotá : Oveja Negra, 1985.

FACIO, Gonzalo J. La paz de Centroamérica y la acción del Grupo de Contadora. Relaciones internacionales. Heredia, (8-9): 23-35, 1984.

FLORES PINEL, Fernando. Ni por la guerra ni por la paz: el impase del Grupo de Contadora. Estudios Centroamericanos. San Salvador, 38 (415-416): 531-534, mayo/jun. 1983.

GRABENDORFF, Wolf. El papel de las potencias regionales en la crisis Centroamericana: comparación entre México, Venezuela, Cuba y Colombia. Revista occidental Tijuana, 1 (4): 437-460, 1984. (Edición especial).

HERNÁNDEZ ALCERRO, Jorge Ramón. La crisis Centroamericana y las negociaciones de Contadora. Revista de Derecho, Tegucigalpa, 17(18) :23-25, 1986

GUTIÉRREZ, Carlos José. Costa Rica, Contadora y la democracia en Centroamérica. Relaciones Internacionales. Heredia, (10) :63-68, 1985.

HERRERA ZUÑIGA, René \& Chavarría, Manuel. México en Contadora: una búsqueda de límites a su compromiso en Centroamérica. Foro Internacional. México, 24(4) :458-483, abr./jun. 1984.

KAUFMAN PURCEL, Susan. La verdad sobre Contadora. Revista Occidental. Tijuana, 3(1) :47-69, 1986.

KISSINGER, Henry. Em busca da paz na América Central. O Estado de S. Paulo. São Paulo, 6 de setembro de 1987. Exterior.

MORALES, Cesáreo. Contadora y la estrategia de Estados Unidos en Centroamérica: evolución y perspectivas. Cuadernos Americanos. México, 44(1) : 45-62, ene./feb. 1985.

MUÑOZ LEDO, Jésus Cabrera. La seguridad nacional de México y la pacificación de Centroamérica. Revista mexicana de política exterior. México, (16) :11-13, jul./set. 1987. 
OPPENHEIM, L. Tratado de derecho internacional público. Barcelona, Bosch, 1966, v.1. t.2.

PAZ AGULAR, Ernesto. Evolución reciente de la política exterior de Honduras: balance y perspectivas. Relaciones Internacionales. Heredia, 4(6) : 123-130, 1986 (Número extraordinário).

PAZ BARNICA, Edgardo. Lecciones de derecho internacional público. Madrid, Cultura Hispánica, 1984.

PELICER, Olga. Reflexiones sobre la acción del Grupo de Contadora. Estudios Centroamericanos. San Salvador, 41(456) : 898-906, oct. 1986.

ROUSSEAU, Charles. Derecho internacional público. 3.ed., Barcelona, Ariel, 1966 SEPÚLVEDA, César. Opciones entre diplomacia y hegemonia. La misión de Contadora. Revista mexicana de política exterior. México, (17) :8-12, oct./dic. 1987

SOARES, Guido Fernando Silva. Órgãos das soluções extrajudiciais de litigios. São Paulo : Revista dos Tribunais, 1985.

Examen de los principales tratados bilaterales y multilaterales vigentes entre países latinoamericanos (no pertenecientes al sistema interamericano) sobre solución pacífica de conflictos, com especial énfasis en su posible hermeticidad y aplicaciones. In: Integración solidaria para el mantenimiento de la paz en América Latina. Caracas, Instituto de Altos Estudios de América Latina. /1989/

TOKATLIAN, Juan Gabriel. Contadora: tres opciones básicas. Nueva Sociedad. Caracas (87) :6-10, ene./feb. 1987.

TREVIÑO HUERTA, Luisa. Contadora: punto de encuentro entre América Latina y Europa Occidental. Revista de Estudios Internacionales. Madrid, 7(3) :821836m, jul./ set. 1986.

TRINDADE, Antonio Augusto Cançado. Aspectos institucionais das relações internacionais na América Latina. Política e Estratégia. São Paulo, 2(1) : 2852 jan./ mar. 1984.

VALERO, Ricardo. América Central la paz y la tormenta. Revista Mexicana de Política Exterior. México, (13) .15-18, oct./ dic. 1986. 